\title{
UNREPORTED URINARY AND ANAL INCONTINENCE IN WOMEN
}

\author{
Humera Ansar, Fauzia Adil and Aftab A. Munir
}

\begin{abstract}
OBJECTIVE: To know the occurrence of unreported urinary and anal incontinence in women and its relation with age, parity, pregnancy, childbirth and other factors.

DESIGN: A descriptive study.

SETTING: Study was conducted at department of Obstetrics and Gynaecology, Isra University Hospital, Hyderabad from January 2002 to December 2003.

METHODS: Convenience sample of 858 women was taken to fill in a pre-formed questionnaire. All those who presented with urinary or anal incontinence were excluded from the study. The main outcome measures included occurrence and duration of incontinence as well as its relation to age, parity and other factors.

RESULTS: Out of 858 women included in the study, 207 (24.12\%) women admitted to have incontinence; 205 (23.89\%) had urinary incontinence, 21 (2.44\%) women had anal incontinence and among these there were $19(9.26 \%)$ women having combined urinary and anal incontinence. One hundred and thirty eight (67.31\%) females were between 21-40 years of age and 109 $(53.17 \%)$ were between para 1-5. Eighty-one (39.51\%) subjects had urinary incontinence for 5-10 years and $09(42.85 \%)$ females had anal incontinence for $10-15$ years. Sixty-nine (33.65\%) women related the onset of urinary incontinence and $13(61.90 \%)$ related the beginning of anal incontinence to first vaginal delivery. Other events related to the onset of incontinence included first pregnancy, second vaginal delivery, chronic cough, obesity, vaginal prolapse and menopause.

CONCLUSION: Many women attending the Obstetrical and Gynaecological Outpatients department have symptoms of urinary and anal incontinence, but do not complain about these unless asked specifically. It is therefore, important for the gynecologist to ask direct questions regarding bowel and bladder dysfunction to identify such patients.
\end{abstract}

KEY WORDS: Incontinence. Anal Canal. Gynaecology. Pregnancy. Vagina. Delivery.

\section{INTRODUCTION}

The word incontinence means inability to retain, whether it be urine, faeces, flatus or semen. It has been derived from the word 'continere' which means 'to stop'. Incontinence is a distressing condition which although rarely life threatening, severely and adversely affects all aspects of a woman's quality of life. Urinary incontinence has long been described as an involuntary loss of urine, which is objectively demonstrable and becomes a social or hygienic problem (International Continence Society) ${ }^{1}$. Recently, the International Continence Society have documented that this definition relates the complaint to quality of life issues. Thus, a new definition has been brought forward in 2002 as "Urinary incontinence is the complaint of any involuntary leakage of urine" ${ }^{2}$. Overall, studies that validated incontinence objectively had lower prevalence estimates (23.5\%) than those dependant on interview skills only $(29.5 \%)$. Epidemiological studies conducted in the United States seldom confirm urinary incontinence objectively and have higher prevalence rate $(37 \%$ in 13 studies) than do Europeans (26\% in 19 studies) and British (29\% in 8 studies) series ${ }^{3}$. Inconsistent non-standardized definitions are also problematic in epidemiological studies of anal incontinence. Fecal incontinence refers to incontinence of solid or liquid stools and represents a sub-set of anal incontinence, which refers to both fecal, and flatus incontinence. Frequent flatus incontinence can be as bothersome as infrequent fecal incontinence and studies that discount the incontinence of flatus under-estimate the prevalence of significant anal incontinence.

It is not uncommon for urinary and anal incontinence to co-exist in the same woman or to develop at different times. Jackson and co-workers have reported that $31 \%$ of women with anal incontinence have concurrent urinary incontinence ${ }^{4}$. The relationship among urinary incontinence, anal incontinence and other forms of pelvic floor dysfunction are complex and multifactorial. To 
understand these relationships pelvic floor anatomy can be artificially divided into passive and active structures. Passive structures include the pelvic bones and connective tissue. The active support structures include the 'neurologic wiring' to the pelvic floor muscles and the muscles themselves ${ }^{5}$. Damage to these structures may lead to loss of support and loss of normal function of the urethra, bladder and anorectum. Over a time, this damage can result in isolated or combined pelvic organ prolapse, urinary incontinence and anal incontinence.

The financial burden of urinary incontinence has been estimated at 26.3 billion each year for diagnosis, care and protective garments, surgical and conservative treatment and related health complications ${ }^{6}$. Anal incontinence affects women eight times more often than men $^{7}$. The reason of this difference is considered to be childbirth $^{8}$. Fecal incontinence affects $1-16 \%$ of women ${ }^{9}$. Little is known about the natural history of urinary and anal incontinence, including age of onset, incidence rates, progression and spontaneous remission. To date, most of the studies have been conducted in whites and data are needed on the occurrence in non-white ethnic groups. Though, incontinence is a symptom of many conditions, defining risk factors would be extremely useful for identifying high-risk persons and remediable environmental causes. While age, gender and parity are established risk factors, many other factors have been suggested but not rigorously proven. Risk factor identification is essential for concrete efforts for prevention ${ }^{3}$. As mentioned in various studies that incontinence is affecting millions of people world wide and there may be many more in the community who remain un-recognized. Thus, this problem has been labeled as "The Silent epidemic"10. This study aimed at detecting the occurrence of asymptomatic urinary and anal incontinence. In addition, the duration of these symptoms, events related to its onset and relation to childbirth were investigated. Analysis of these could result in setting up preventive strategies.

\section{PATIENTS AND METHODS}

The data for this study was collected through a questionnaire at the department of Obstetrics and Gynaecology of Isra University Hospital, Hyderabad, Sindh from January 2002 to December 2003. It was a single centre study in which the relative frequency of urinary and anal incontinence was recorded in patients attending the Outpatients Department (OPD). A total of 858 women was recruited for study who visited OPD for various Obstetrical and Gynaecological problems. All those women who presented with the symptoms of urinary or anal incontinence were excluded from the study. Urinary incontinence was described as complaint of any involuntary leakage of urine while anal incontinence included both fecal and flatus incontinence. Women having involuntary loss of urine, flatus or faeces at present or any previous episode for which no medical help has been sought were labeled as asymptomatic and minimum of three episodes were taken as a cut off to label them as incontinent. The volunteers answered a set of standardized questions including age, parity, type, frequency and duration of urinary and / or anal incontinence. They were also asked that whether they can relate the onset of their symptoms to any event including pregnancy, childbirth, menopause, obesity, chronic cough, constipation or any other factor. The questionnaire also included their obstetric, medical and surgical history. After filling in the questionnaire, a midstream urine sample was sent of all those women with history of urinary incontinence to exclude any infection.

\section{RESULTS}

A total of 207 women gave the history of incontinence out of 858 women included in the study. Out of these, $205(23.89 \%)$ gave positive history of urinary incontinence and 21 women $(2.44 \%)$ had anal incontinence. Of these 205 women, 186 (90.73\%) had only urinary incontinence while 19 (9.26\%) had combined anal and urinary incontinence. There were $2(9.52 \%)$ out of 21 women who had only flatus incontinence. Out of $19(90.47 \%)$ women having combined incontinence, $5(23.80 \%)$ had only fecal incontinence while $14(66.66 \%)$ had both faecal and flatus incontinence. The age of the patients in our series ranged from 16-60 years. Majority of the women was in their reproductive age group between 21-40 years (Figure I). Parity varied from nullipara to parity greater than 10. Although 109 patients $(53.17 \%)$ had parity between $1-5$, there were 23 (11.21\%) women who developed incontinence while they were pregnant for the first time (Figure II). Duration of symptoms was varying from few months to greater than 20 years. Seven patients (3.4\%) who had urinary incontinence for more than 20 years were mostly postmenopausal and grand multipara. While $09(42.85 \%)$ women having anal incontinence were suffering for 10-15 years without seeking any help (Figure III). There was no history of any perineal surgery in our study population. Moreover, on inquiry these women had symptoms of stress incontinence or urge incontinence and some of them had mixed symptoms.

On interviewing, majority of our women were able to 
describe the relationship of some event to the onset of their problem. First vaginal delivery was highlighted as the major event related to the onset of both urinary and anal incontinence. Others included second vaginal delivery, first pregnancy, chronic cough, obesity, menopause and vaginal prolapse. Twentyseven women (13.17\%) were not able to identify association to any event (Table I).

\section{FIGURE I:}

AGE DISTRIBUTION OF WOMEN HAVING INCONTINENCE $(n=207)$

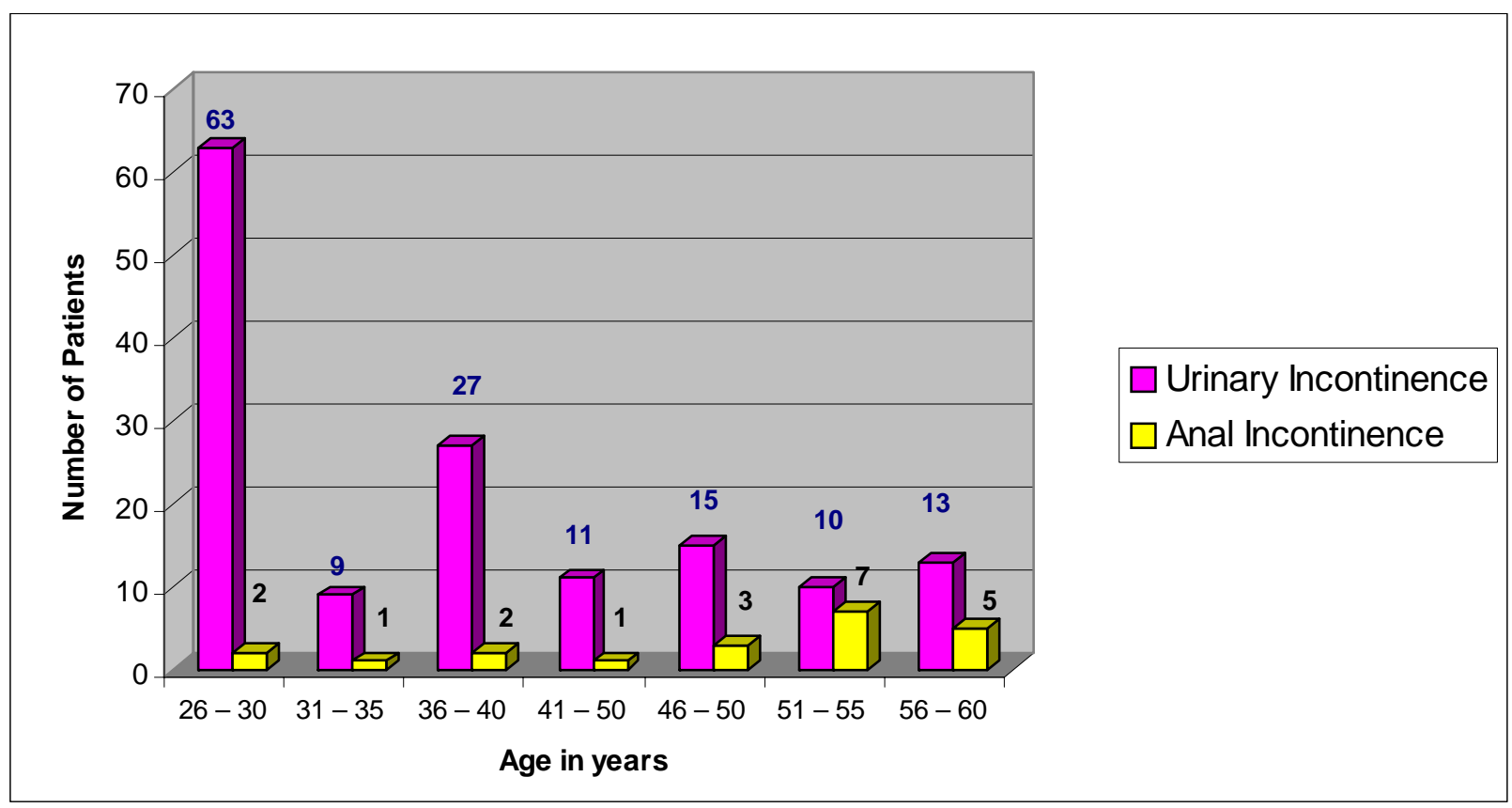

FIGURE II:

PARITY STATUS OF WOMEN WITH INCONTINENCE

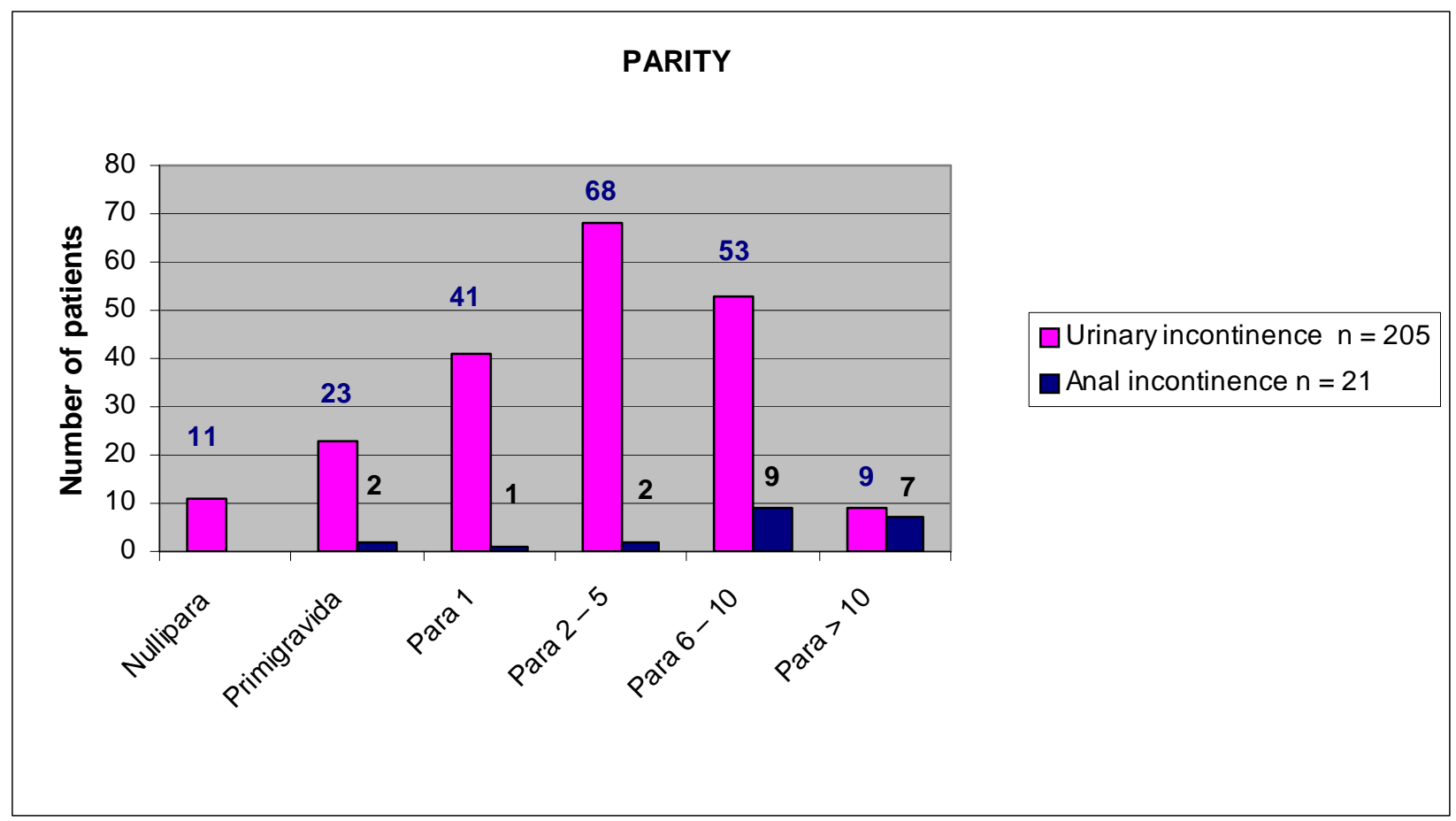




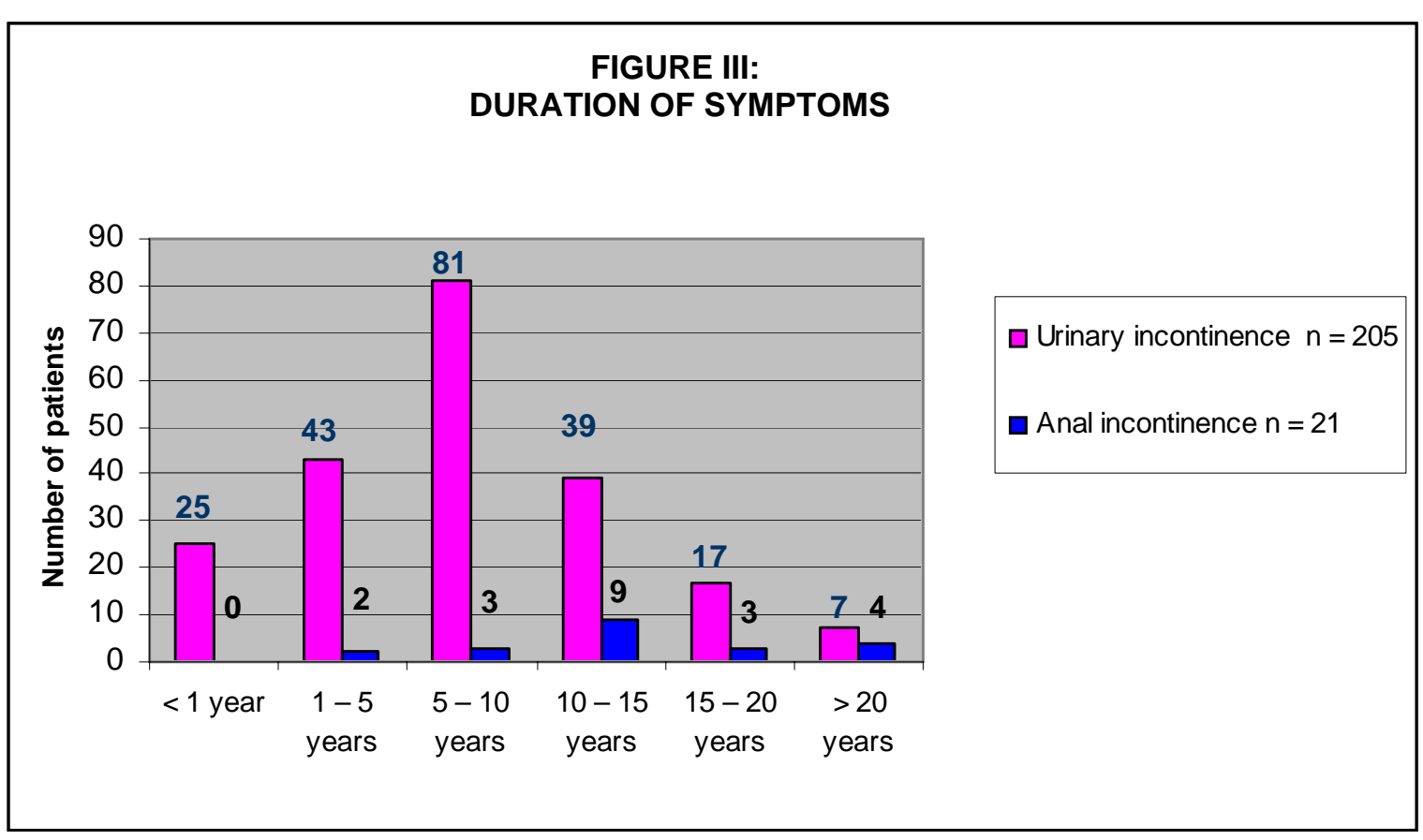

TABLE I:

EVENTS RELATED TO THE ONSET OF INCONTINENCE

\begin{tabular}{|l|c|c|c|c|}
\hline \multirow{2}{*}{ Event } & \multicolumn{2}{c|}{ Urinary incontinence } & \multicolumn{2}{c|}{ Anal incontinence } \\
\cline { 2 - 5 } & $\mathbf{n = 2 0 5}$ & $\%$ & $\mathbf{n = 2 1}$ & $\%$ \\
\hline No significant association found & 27 & 13.17 & - & - \\
\hline First trimester of first pregnancy & 23 & 11.21 & - & - \\
\hline Last trimester of first pregnancy & 31 & 15.12 & - & - \\
\hline First vaginal delivery & 69 & 33.65 & 13 & 61.9 \\
\hline Second vaginal delivery & 37 & 18.04 & 04 & 19.04 \\
\hline Chronic cough & 03 & 1.46 & 01 & 4.76 \\
\hline Obesity & 03 & 1.46 & 02 & 9.52 \\
\hline Vaginal prolapse & 07 & 3.41 & - & - \\
\hline Menopause & 05 & 2.43 & 01 & 4.76 \\
\hline
\end{tabular}

\section{DISCUSSION}

Over 200 million people worldwide experience the problems associated with urinary incontinence ${ }^{11}$ and most of them are women. It affects over $50 \%$ of women at sometime in their lives ${ }^{12}$ and women aged 25-50 years are at increased risk. In this study, 138 (67.31\%) patients were between 21-40 years of age. Also, the prevalence increases with age, approximately 5 percent of women between 15 and 44 years of age are being affected, rising to 10 percent of those aged between 45 and 64 years and approximately 20 percent of those greater than 65 years $^{13,14}$. As most of the women interviewed in this study belonged to the reproductive age group, the highest number of patients with incontinence belonged to this group.

More than $50 \%$ of our population had parity $1-5$ but presence of these symptoms in nulliparas and primigravidas indicates that factors other than childbirth are also of concern. Farell SA studied urinary incontinence in primiparas and concluded that caesarean delivery at any stage of labour reduces post partum urinary incontinence as compared to 
vaginal delivery ${ }^{15}$. Duration of symptoms of urinary incontinence varied from few months to more than 20 years. While 149 patients $(72.68 \%)$ had the symptoms for less than 10 years, there were 07 (3.4\%) women who had been suffering from urinary incontinence for more than 20 years. Norton et al (1988) have showed that $25 \%$ of women suffering from urinary incontinence wait for more than 5 years before seeking help.

Ample data confirms that neuromuscular damage contributes to loss of support of the pelvic floor leading to urinary and anal incontinence ${ }^{16-19}$. This damage links to childbirth ${ }^{20}$, chronic constipation and pelvic organ prolapse. Thirty-five percent of women without gross evidence of perineal laceration at delivery have occult injury to the anal sphincter complex on the basis of endoanal sonography ${ }^{21}$. Moreover, it is not surprising that $20-30 \%$ of women experience symptoms of stress incontinence following a single vaginal delivery ${ }^{22}$. Similar results were seen in this study population that is 69 women (33.65\%) developed urinary incontinence and 13 (61.9\%) developed anal incontinence after first vaginal delivery. But, identification of other factors related to its onset will help us to set up guidelines for primary prevention.

\section{CONCLUSION}

Many women attending the OPD have symptoms of urinary and anal incontinence but do not complain about these unless asked specifically and it is not difficult to imagine the impact that incontinence has on the quality of life as sufferers may be socially isolated and depressed. In a setting of gynaecology clinic, these conditions are commonly encountered in association with other disorders of the pelvic floor. It is therefore, important for the gynaecologist to ask direct questions regarding bowel and bladder dysfunction $^{23}$. This will enable us to set up preventive strategies including training and supervision of obstetric staff, postmenopausal estrogen replacement, regular pelvic floor exercises specially after vaginal delivery ${ }^{23,24}$ and good bladder habits from an early age.

\section{REFERENCES}

1. Cardozo L. Urinary incontinence. Dewhurst's Textbook of Obstetrics and Gynaecology for post graduates. Sixth edition. 1999. Blackwell Science: Pp. 474-504.

2. Abrams $P$, Cardozo L, Fall $M$ et al. The standardization of terminology of lower urinary tract function. Am J Obstet Gynecol 2002;187(1): 116-126.
3. Bump RC, Norton PA. Epidemiology and natural history of pelvic floor dysfunction. Obstet Gynecol Clin North Am 1998; 25 (4):723-746.

4. Jackson SL, Weber AM, Hull TL et al. Fecal incontinence in women with urinary incontinence and pelvic organ prolapse. Obstet Gynecol 1997; 89: 423-427.

5. Strohbehn K. Normal pelvic floor anatomy. Obstet Gynecol Clin North Am 1998; 25 (4): 683-705.

6. Elia G, Bergman J, Dye TD. Familial incidence of urinary incontinence. Am J Obstet Gynecol 2002;187 (1): 53-55.

7. Fynes $M, O$ O'Herlihy $C$. The influence of mode of delivery on anal sphincter injury and fecal continence. The Obstetrician and Gynaecologist 2001; 3 (3): 120-126.

8. Morakinyo EO, Spencer JAD. Anal and urinary incontinence after childbirth. The Obstetrician and Gynaecologist 2001; 3 (1): 41-44.

9. Khullar V, Damiano R, Hobson PT et al. Prevalence of faecal incontinence among women with urinary incontinence. $\mathrm{Br} \mathrm{J}$ Obstet Gynecol 1998;105 (11): 1211-1213.

10. Rane A. Urinary incontinence: the silent epidemic. Orgyn 2002; 13 (2): 40-41

11. Reilly BO, Kelleher C. Urinary urge incontinence: a review of current papers. The Obstetrician and Gynaecologist 2002; 4 (2): 111-115.

12. James $M C$ and Abrams $P$. Female urinary incontinence. Europeon Urology Update Series. 1997; 6: 97-104.

13. Laycock $\mathrm{J}$ and Homes DM. The place of physiotherapy in the management of pelvic floor dysfunction. The Obstetrician and Gynaecologist 2003; 5 (4):194-9.

14. Campbell $S$ and Monga A. Urogynaecology. Gynaecology by Ten Teachers. $17^{\text {th }}$ Edition 2000; Pp. 205-216.

15. Farell SA, Allen VM and Baskett TF. Parturition and urinary incontinence in primiparas. Obstet Gynecol 2001; 97 (3): 350-6.

16. Allen RF, Hoster GL, Smith RB et al. Pelvic floor damage and childbirth: a neurological study. $\mathrm{Br} \mathrm{J}$ Obstet Gynecol 1990; 97: 770-779.

17. Kamm MA. Obstetric damage and fecal incontinence. Lancet 1994; 344: 730-733. 
18. Smith ARB, Hosker GL and Warrell DM. The role of pudendal nerve damage in the aetiology of genuine stress incontinence in women. $\mathrm{Br} \mathrm{J}$ Obstet Gynaecol 1989; $96: 29-32$.

19. Smith ARB, Hosker JL and Warrell DW. The role of partial denervation of the pelvic floor in the aetiology of genitourinary prolapse and stress incontinence of urine: a neurophysiologic study. Br J Obstet Gynaecol 1989; 96: 24-28.

20. Sultan $\mathrm{AH}$. Anal incontinence after childbirth: current opinion. Obstet Gynecol. 1997; 9: 230324.
21. Sultan $\mathrm{AH}, \mathrm{Kamm} \mathrm{MA}$, Hudson $\mathrm{CN}$ et al. Anal sphincter disruption during vaginal delivery. $\mathrm{N}$ Engl J Med 1993; 1905-1911.

22. Sleep J and Grant A. West Berkshire perineal management trial: three year follow up. BMJ 1987; 295: 749-751.

23. Sturdee D, Olah K and Keane D. Anal incontinence: the role of Obstetrician and Gynaecologist. The year book of Obstetrics and Gynaecology by Royal College of Obstetrics and Gynaecology 2001; 9: 170-187.

24. Reilly ETC, Freeman RM, Waterfield MR et al. Prevention of postpartum stress incontinence in

AUTHOR AFFILIATION:

Dr. Humera Ansar (Corresponding Author)

Associate Professor

Department of Obstetrics and Gynaecology, Isra University

P.O.Box - 313, Hala Road, Hyderabad.

E - mail : ansarhumera@hotmail.com

Dr. Fauzia Adil

Associate Professor

Department of Obstetrics and Gynaecology, Isra University

P.O.Box - 313, Hala Road, Hyderabad.

Prof. Aftab A. Munir

Department of Obstetrics and Gynaecology, Isra University

P.O.Box - 313, Hala Road, Hyderabad. 